\title{
Synthesis by anodic-spark deposition of Ca- and P-containing films on pure titanium and their biological response
}

Oksana Banakh $^{1 *}$, Tony Journot ${ }^{1}$, Pierre-Antoine Gay ${ }^{1}$, Joël Matthey ${ }^{1}$, Catherine Csefalvay ${ }^{1}$, Oleg Kalinichenko ${ }^{2}$, Olha Sereda ${ }^{3}$, Mira Moussa $^{4}$, Stéphane Durual ${ }^{4}$, Lyubov Snizhko ${ }^{2}$

${ }^{1}$ Haute Ecole Arc Ingénierie (HES-SO), Eplatures-Grise 17, CH-2300 La Chaux-de-Fonds, Switzerland

${ }^{2}$ Ukrainian State University of Chemical Technology (SHEI), Gagarin av. 8, Dnepropetrovsk, UA-49005, Ukraine

${ }^{3}$ Centre Suisse d'Electronique et de Microtechnique (CSEM), Rue Jaquet-Droz 1, CH-2000 Neuchâtel, Switzerland

${ }^{4}$ Laboratory of Biomaterials, University of Geneva, rue Barthelemy Menn 19, CH-1205 Geneva, Switzerland

\begin{abstract}
The purpose of this work is to characterize the anodized layers formed on titanium by anodicspark deposition in a electrolyte containing $\mathrm{Ca}$ and $\mathrm{P}$ ions, $\mathrm{Ca}_{3}\left(\mathrm{PO}_{4}\right)_{2}$, studied for the first time. The oxidation experiments were performed at different periods of time and using different concentrations of electrolyte. The influence of the process parameters (time of electrolysis and electrolyte concentration) on the surface morphology and chemical composition of the anodized layers was studied. It has been found that it is possible to incorporate $\mathrm{Ca}$ and $\mathrm{P}$ into the growing layer. A response of the anodized layers in a biological medium was evaluated by their immersion in a simulated body fluid. An enrichment of titanium and a simultaneous loss of calcium and phosphorus in the layer after immersion tests indicate that these coatings should be bioresorbable in a biological medium. Preliminary biological assays were performed on some anodized layers in order to assess their biocompatibility with osteoblast cells. The cell proliferation on one selected anodized sample was assessed up to 21 days after seeding. The preliminary results suggest excellent biocompatibility properties of anodized coatings.
\end{abstract}

Keywords: titanium, calcium-phosphate coating, anodization, anodic-spark deposition, SBF test

* Corresponding author. Tel.: +41 7655725 20, fax: +41 3293029 30, E-mail address: oksana.banakh@he-arc.ch (O.Banakh)

\section{Introduction}

Titanium and its alloys are successfully used in medicine as implant materials (dental implants and orthopedic prostheses) [1]. The biological activity of an implant (osteointegration, 
resorbability) plays an important role on its durability and performance. A successful osteointegration strongly depends on an ability of the implant to form a hydroxyapatite (HA) surface layer in presence of the body fluid. Therefore, in order to improve the osteointegration, the titanium implants are often coated with hydroxyapatite layers.

Recently, surface modification of titanium and its alloys by anodic-spark deposition, ASD (or plasma electrolytic oxidation, PEO) gained much attention [2]. This technique results in rough and porous ceramic layers, whose composition depends on the chemical content of the electrolyte employed and on the substrate material. However, anodic oxide coatings grown on titanium and its alloys are considered bio inert materials that do not cause the formation of bone tissue around them. One way to render the surface properties of oxidised titanium bioactive is by the incorporation of calcium and phosphorous ions into the growing layer from electrolyte during ASD process [3], which can influence the degree of their biodegradation (or bioresorbability).

The coating ability to be resorbed in the biological environment is an important property as it allows to regenerate a new bone in vicinity of the implant. Ideally, the chemical composition of the coating must be close to the composition of calcium hydroxyapatite $\mathrm{Ca}_{10-\mathrm{x}}\left(\mathrm{HPO}_{4}\right)_{\mathrm{x}}\left(\mathrm{PO}_{4}\right)_{6-}$ $x(\mathrm{OH})_{2-\mathrm{x}}$, which comprises a $\mathrm{Ca} / \mathrm{P}$ molar ratio in the range of 1.5-1.67. The chemical composition of amorphous calcium phosphates (ACPs) strongly depends on the $\mathrm{pH}$ value and the concentrations of mixing solutions [4]. For example, ACPs with $\mathrm{Ca} / \mathrm{P}$ ratios in the range of 1.18 (precipitated at $\mathrm{pH}=6.6$ ) to 1.53 and even to 2.5 (precipitated at $\mathrm{pH}=11.7$ ). On the other hand, the dissolution of different phosphates depends on their composition. Thus, $\mathrm{Ca}$ - deficient hydroxyapatite with $\mathrm{Ca} / \mathrm{P}$ ratio of $1.5-1.67, \mathrm{Ca}_{10-\mathrm{x}}\left(\mathrm{HPO}_{4}\right)_{\mathrm{x}}\left(\mathrm{PO}_{4}\right)_{6-\mathrm{x}}(\mathrm{OH})_{2-\mathrm{x}}$, has a solubility $0,0094 \mathrm{~g} / \mathrm{l}$ at $25^{\circ} \mathrm{C}$ and $\mathrm{pH}=6.5-9.5$, while hydroxyapatite with $\mathrm{Ca} / \mathrm{P}$ ratio of 1.67 , $\left.\mathrm{Ca}_{10} \mathrm{PO}_{4}\right)_{6}(\mathrm{OH})_{2}$, at the same temperature has a solubility of $0.0003 \mathrm{~g} / \mathrm{l}$ even at higher $\mathrm{pH}(9.5$ 12) $[5]$.

ACPs coatings can be prepared by anodic spark oxidation from electrolytes containing trisodium phosphate and calcium hydroxide [6], dihydrophosphate $\mathrm{Ca}\left(\mathrm{H}_{2} \mathrm{PO}_{4}\right) \cdot 2 \mathrm{H}_{2} \mathrm{O}$ [7] and calcium acetate, $\mathrm{Ca}\left(\mathrm{OOCCH}_{3}\right)_{2}$ in combination with a calcium complexing agent [2]. Calcium hydrophosphates, like $\left(\mathrm{CaHPO}_{4}\right)$ and $\left.\mathrm{CaHPO}_{4} \cdot 2 \mathrm{H}_{2} \mathrm{O}\right)$ are thermodynamically unstable at $\mathrm{pH}>$ 6.7, and transform into more stable calcium phosphates like $\mathrm{Ca}_{3}\left(\mathrm{PO}_{4}\right)_{2}$ [8].

Another way to increase the biological activity of the coatings is by a specific surface morphology. A highly porous surface morphology allows a circulation of biological fluids. Porosity is closely related to the mechanical properties of bone implant materials. Implant 
porosity has a direct effect on osteogenesis and integration with natural bone. Pore size of 80$250 \mu \mathrm{m}$ was recommended to provide bone ingrowth into metallic implants [9].

The objective of this work is to produce $\mathrm{Ca}$ - and $\mathrm{P}$ - containing passive anodized layers by anodic spark oxidation of commercially pure titanium (CP-4) and study their chemical composition, chemical bonds, surface morphology as well as their degradability in simulated body fluid (SBF). As these $\mathrm{Ca}$ - and $\mathrm{P}$ - containing titanium anodized layers are dedicated to medical applications (implants), a preliminary study to evaluate a cell biocompatibility of the anodized layers was also performed. In present work, the layers were anodized using a $\mathrm{Ca}_{3}\left(\mathrm{PO}_{4}\right)_{2}$ solution as electrolyte. This choice was motivated by the fact that a $\mathrm{Ca}_{3}\left(\mathrm{PO}_{4}\right)_{2}$ has a higher $\mathrm{Ca} / \mathrm{P}$ molar ratio (1.5) as compared to other electrolytes, used in the previously reported studies performed by different research groups [10]. To our knowledge, this electrolyte has not been investigated in the past. In summary, the aim of this work was to initiate a systematic study of the influence of the process parameters (time of electrolysis, electrolyte concentration) on the coating physical and chemical properties ( $\mathrm{Ca} / \mathrm{P}$ molar ratio), while using a new electrolyte, $\mathrm{Ca}_{3}\left(\mathrm{PO}_{4}\right)_{2}$ solution, during ASD process. For the first time, feasibility of this electrolyte to obtain Ca- and P- containing anodized layers on titanium alloys was demonstrated.

We believe that our results are encouraging and will initiate future investigations, especially those targeting the optimisation of the process parameters to obtain surface functional properties fitted to application requirements.

\section{Experimental details}

The material used for anodic spark oxidation experiments was commercially pure titanium $\mathrm{Ti}$ CP- 4 (ASTM B348 Grade 4, Signer Titanium AG) of the following composition C - 0,1 wt. $\%, \mathrm{Fe}-0,5$ wt. $\%, \mathrm{H}-0,015$ wt. $\%, \mathrm{~N}-0,05$ wt. $\%, \mathrm{O}-0,4$ wt. $\%, \mathrm{Ti}-$ rest). The disk-shaped samples with a diameter of $10 \mathrm{~mm}$ and a thickness of $5 \mathrm{~mm}$ were cut from the bar and mechanically polished to remove cutting strides. Before anodization, the samples were cleaned in acetone and ethanol in the ultrasonic bath and rinsed in distilled water. After cleaning, the samples were chemically treated in a most commonly-used pickling solution, a mixture of $48 \%$ $\mathrm{HF}$ and $70 \% \mathrm{HNO}_{3}$ (volume ratio 1:3) during $60 \mathrm{sec}$ at room temperature [11]. Anodizing was performed using a home-made pulsed power supply operated in a galvanostatic mode with a current density of $400 \mathrm{~A} / \mathrm{m}^{2}$. A unipolar half-wave pulses with positive voltages $U_{p}$ ranging from 400 to $600 \mathrm{~V}$ and a frequency of $50 \mathrm{~Hz}$ were used. 
The anodization electrolyte was a $\mathrm{Ca}_{3}\left(\mathrm{PO}_{4}\right)_{2}$ solution (with molar ratio $\mathrm{Ca} / \mathrm{P}=1.5$ ), with the concentration varied between 2 to $10 \mathrm{~g} / \mathrm{l}$ (corresponding to 6,4 and $32 \mathrm{mmol} / \mathrm{l}$ ). In order to dissolve the reactant, we used a $0.5 \mathrm{M}$ solution of Trilon B ( $\left.\mathrm{Na}_{2} \mathrm{EDTA}\right)$. As the formation of soluble complex containing the cations $\mathrm{Ca}^{2+}$, namely $[\mathrm{CaY}]^{2-}$, where $\mathrm{Y}=$ $\left[(\mathrm{OOC}) \mathrm{NCH}_{2} \mathrm{CH}_{2} \mathrm{~N}(\mathrm{COO})_{2}\right]^{4-}$ is only possible in a basic solution, we added $2 \mathrm{M}$ solution of $\mathrm{KOH}$ to keep $\mathrm{pH}=13$. Each electrolyte solution was completed to 11 with water.

The oxidation time was fixed at 3, 6, 9, 12 and $15 \mathrm{~min}$. The electrolyte during anodization was cooled down to about $40^{\circ} \mathrm{C}$ by a cold water circulation. After anodization, the samples were rinsed with distilled water and dried in air.

The anodized samples were subjected to SBF (simulated body fluid) solution in order to evaluate their degradation (dissolution) in biological medium. SBF solution was prepared using a recipe given in [12] and called Kokubo's SBF or K-SBF. The K-SBF was prepared by dissolving $6.057 \mathrm{~g}$ of TRIS (tris-hydroxyl-methyl amino-methane) $\left.\left[\left(\mathrm{CH}_{2} \mathrm{OH}\right)_{3} \mathrm{CNH}_{2}\right)\right]$ in 600 $\mathrm{ml}$ of distilled water. The solution $\mathrm{pH}$ was adjusted to 7.4 at $37^{\circ} \mathrm{C}$ by adding $5 \mathrm{M} \mathrm{HCl}$ dropwise. Distilled water was added to the solution to reach the volume of 11 . In this solution the following reagents were finally dissolved: $7.995 \mathrm{~g} \mathrm{NaCl}, 0.353 \mathrm{~g} \mathrm{NaHCO}_{3}, 0.224 \mathrm{~g} \mathrm{KCl}, 0.174$ $\mathrm{g} \mathrm{K}_{2} \mathrm{HPO}_{4}, 0.71 \mathrm{~g} \mathrm{Na}_{2} \mathrm{SO}_{4}, 0.305 \mathrm{~g} \mathrm{MgCl}_{2} \bullet 6 \mathrm{H}_{2} \mathrm{O}$ and $0.368 \mathrm{~g}$ of $\mathrm{CaCl}_{2} \cdot 2 \mathrm{H}_{2} \mathrm{O}$. Each sample was placed in a Petri dish and soaked in a $6 \mathrm{ml} \mathrm{SBF}$ solution for 14 days at $37^{\circ} \mathrm{C}$.

All solutions were prepared using analytical grade reagents manufactured by SigmaAldrich Co. LLC, and deionised water (Purite, 300500 Neptune Ultimate, Purite LTD).

After SBF tests, the samples were rinsed with distilled water and dried in air.

The surface and cross-section morphology of the anodized samples before and after SBF test was characterized using a scanning electron microscopy (SEM, model JEOL JSM-6400). The thickness of the anodized layers was measured by examination of cross-section optical micrographs (model Leica Olympus) and SEM micrographs. The surface porosity size and porosity distribution were calculated from numerical image analysis using an ImageJ/Fiji 1.46 program.

Elemental content in the anodized layers was evaluated by means of X-ray fluorescence analysis (XRF, FISCHERSCOPE® X-RAY XDV®-SDD, Fischer Technology, Inc.) and Energy-Dispersive X-ray Spectroscopy (EDS) coupled to SEM instrument (JEOL Ltd., UK). For some samples, elemental cartography imagines have been carried out. In order to improve the precision of XRF analysis due to data scattering, high number of measurements (minimum 
20) was carried out. The measurement points exceeding $10 \%$ of standard deviation were not taken into account.

Phase analysis was performed by X-ray diffraction (XRD) using a MRD PANalytical diffractometer equipped with $\mathrm{CuK} \alpha$ radiation as the X-ray source (PANalytical B.V., Almelo, NL). The diffraction patterns were recorded by means of the stepwise method within the angular range of $5^{\circ}$ to $90^{\circ}$ in 2 theta axis. The XRD measurements were performed in theta-2theta (Bragg-Brentano) configuration and in grazing incidence configuration. The XRD patterns obtained were compared with the JCPDS standards to identify the phase composition.

The chemical bonding of one anodized layer, after being subjected to SBF test, was investigated by X-Ray Photoelectron Spectroscopy (XPS). To remove surface contaminations, an $\mathrm{Ar}^{+}$ etching ion gun was used $(60 \mathrm{sec})$. XPS spectra were generated under ultra-high vacuum condition using an Axis Ultra instrument (Kratos Analytical, Japan), with a monochromatic AlKa X-ray source $(1486.6 \mathrm{eV})$. The source power was maintained at $150 \mathrm{~W}(10 \mathrm{~mA}, 15 \mathrm{kV})$. The emitted photoelectrons were sampled from a square area of $750 \mu \mathrm{m} \times 350 \mu \mathrm{m}$. Energy windows were recorded for each constituents of interest $(\mathrm{Ca}, \mathrm{Ti}, \mathrm{P}, \mathrm{O})$ with an augmented resolution. XPS spectra were treated using the CasaXPS ${ }^{\circledR}$ software. Peak fitting was done for all photoelectron peaks using Voigt functions after a Shirley type background subtraction.

Preliminary biological assays were performed on some anodized layers in order to assess their biocompatibility with osteoblast cells.

Biological assays were detailed previously [13]. Briefly, human osteoblasts like cells HOS (ATCC ${ }^{\circledR}$ CRL1543 ${ }^{\mathrm{TM}}$ ) (HOBs) were grown on several anodized samples for periods of 3 or 21 days. Resazurin colorimetric assays were used to monitor the proliferation kinetics of HOBs. For each treatment, experiments were conducted up to day 3. For one selected sample (treated during $6 \mathrm{~min}$ at the electrolyte concentration of $\left.6 \mathrm{~g} / \mathrm{l} \mathrm{Ca}_{3}\left(\mathrm{PO}_{4}\right)_{2}\right)$, the experiment was pursued until 21 days after seeding. The choice of the sample was arbitrary. Polystyrene wells were used as a standard for comparison.

The resazurin assay is a colorimetric assay based on the reduction of resazurin (blue) in resofurin (pink). This reduction process is performed by the mitochondrial deshydrogenases from the cells, and not from a chemical interaction with a solid substrate, in our case polystyrene or titanium. Furthermore, the resazurin is added at saturated concentrations, so that an eventual adsorption onto the substrate's surface would be negligible. Finally, the data analysis takes into account a blank condition (titanium and polystyrene without cells, which give the same value anyway), incorporated into the calculations. 


\section{Results and discussion}

\subsection{Thickness and morphology}

Our preliminary study was focused on the investigation of the influence of basic process parameters on the physical and chemical properties of the resulted layers. Two parameters play an important role, the time of electrolysis and the concentration of $\mathrm{Ca}_{3}\left(\mathrm{PO}_{4}\right)_{2}$ in electrolyte. Figure 1 shows the influence of time of electrolysis on the layer thickness for five different electrolyte concentrations used in this study. Figure 2 shows the layer thickness as a function of electrolyte concentration for five different periods of electrolysis time.

Note, that cross-section optical and SEM (Figure 3) observations show that the coating thickness variation is between 10 and $40 \%$, increasing with the deposition time. The error bars are not indicated in Figures 1 and 2 for the sake of clarity.

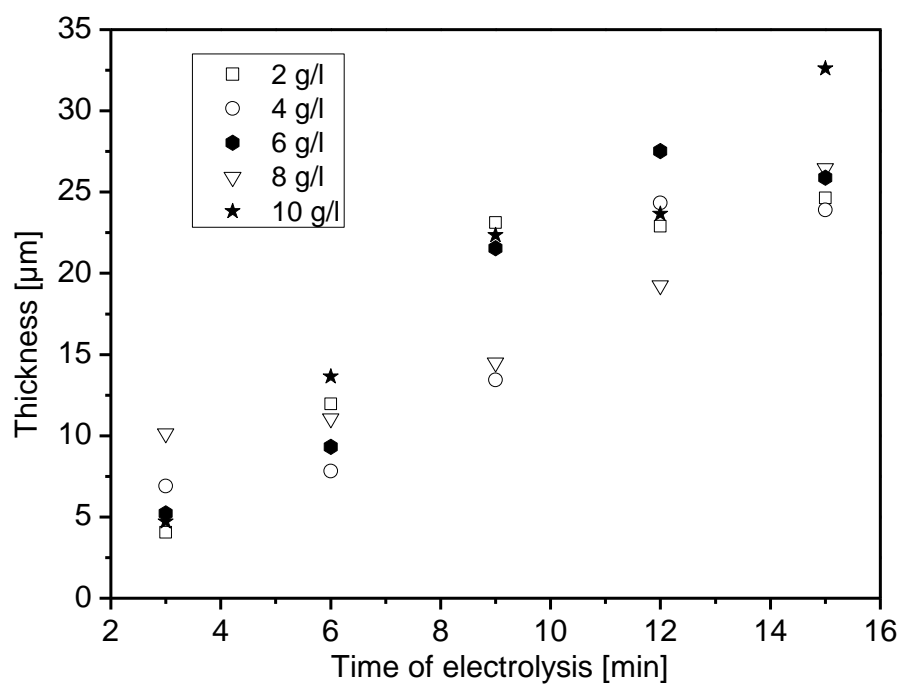

Figure 1. Thickness of the anodized layer as a function of anodization time (for different electrolyte concentrations)

For all $\mathrm{Ca}_{3}\left(\mathrm{PO}_{4}\right)_{2}$ concentrations, the layer thickness increases with the time of electrolysis from 4-10 $\mu \mathrm{m}$ (for $3 \mathrm{~min}$ ) to $23-32 \mu \mathrm{m}$ (for $15 \mathrm{~min}$ ). Anodization at the lowest $\mathrm{Ca}_{3}\left(\mathrm{PO}_{4}\right)_{2}$ concentration $(2 \mathrm{~g} / \mathrm{l})$ results in lower values of thickness, ranging from $5 \mu \mathrm{m}$ (for $3 \mathrm{~min}$ ) to 25 $\mu \mathrm{m}$ (for $15 \mathrm{~min}$ ). The samples anodized in the electrolyte of highest concentration $(10 \mathrm{~g} / \mathrm{l})$ have coating thickness values ranging from $12 \mu \mathrm{m}$ ( $3 \mathrm{~min})$ to $32 \mu \mathrm{m}$ (15 min). Coatings obtained 
with the electrolyte concentration of 4,6 and $8 \mathrm{~g} / \mathrm{l}$ have intermediate values of thickness. It can be concluded that the influence of time of electrolysis on the coating thickness is more apparent than the influence of electrolyte concentration.

Figure 3 shows a cross-section SEM photograph of the sample anodized during 15 min (at electrolyte concentration of $6 \mathrm{~g} / \mathrm{l})$. The cross-section morphology of the other samples is similar, showing a thin barrier-type layer close to the titanium substrate, followed by a thick porous of this oxidized layer is rather dense, however presents some randomly-located inclusions and cracks. The elemental distribution in this layer will be discussed further.

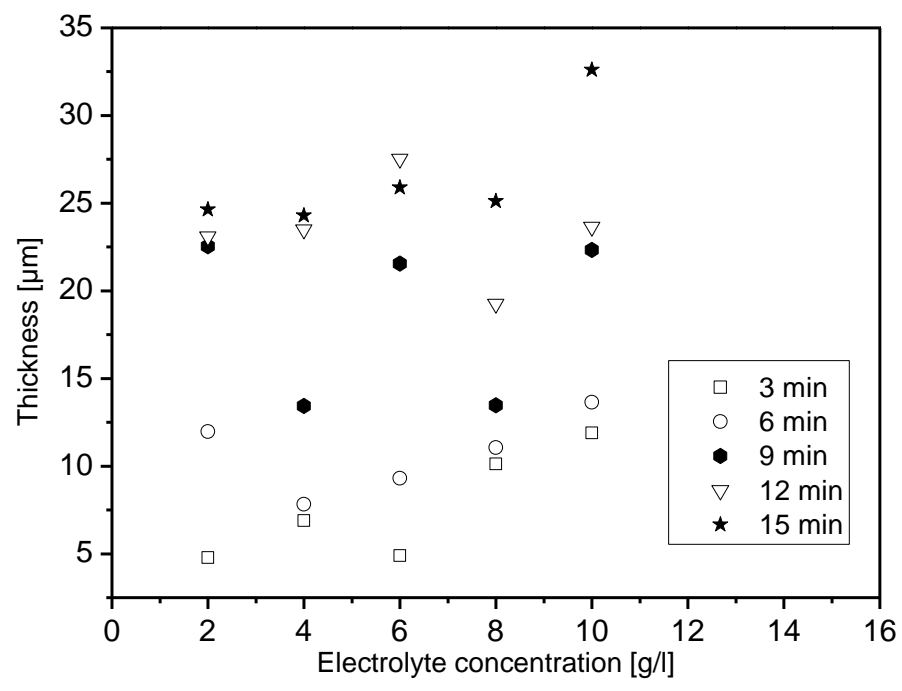

Figure 2. Thickness of the anodized layers as a function of electrolyte concentration (the samples were treated during different periods of time)

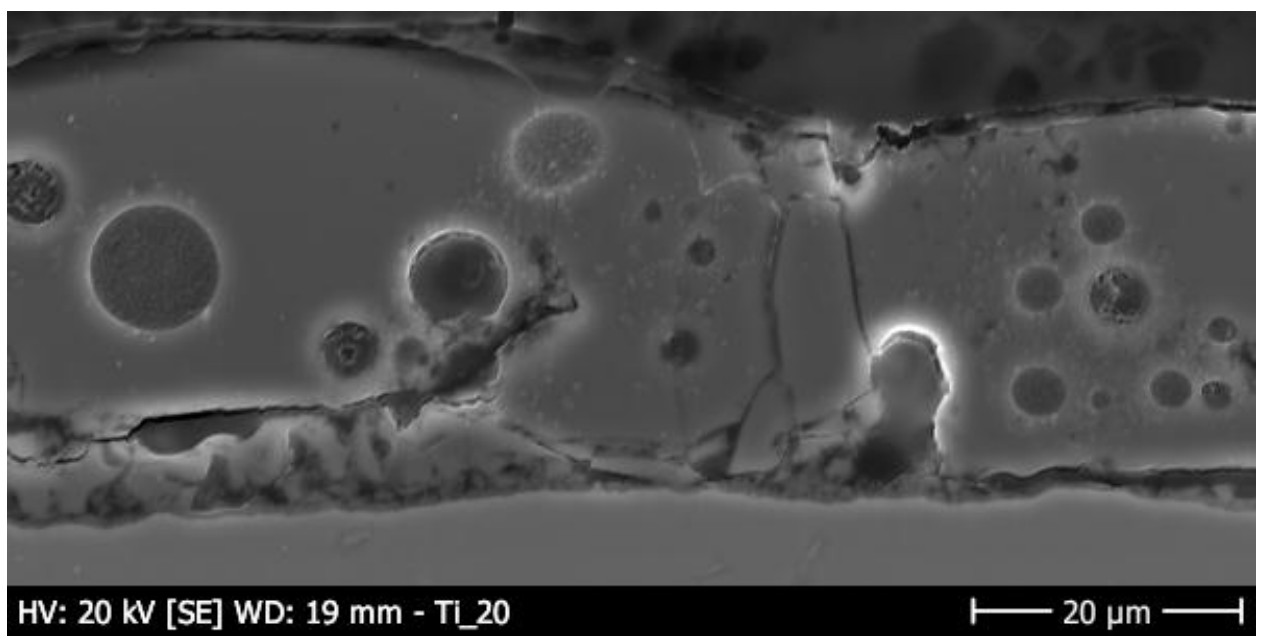


Figure 3. Cross-section SEM photograph of the sample anodized during $15 \mathrm{~min}$ at electrolyte concentration of $6 \mathrm{~g} / \mathrm{l}$

Figure 4 shows the evolution of surface morphology of anodized samples, observed by SEM, with increasing time of electrolysis. All layers exhibit porous, open-void surface morphology. Independently on the electrolyte concentration, increasing the time of electrolysis results in the pore coarsening.

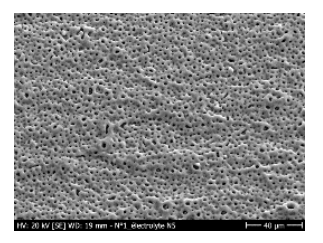

$3 \min$

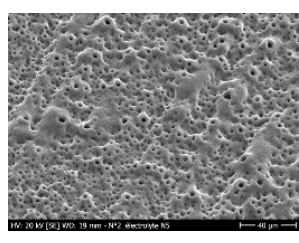

$6 \min$

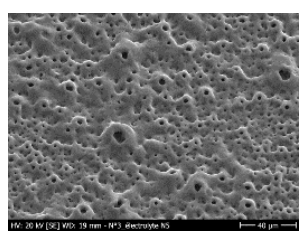

$9 \min$

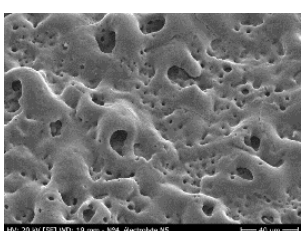

$12 \min$

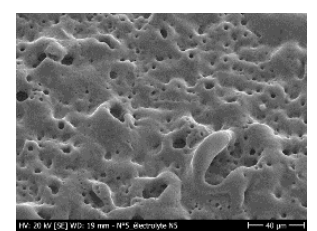

$15 \min$

Figure 4. Evolution of morphology of anodized titanium samples with anodization time (electrolyte concentration $2 \mathrm{~g} / \mathrm{l}$ )

The same effect on morphology was observed with increasing electrolyte concentration for the fixed time of electrolysis. Figure 5 shows the evolution of surface morphology of anodized titanium samples as a function of electrolyte concentration (time of electrolysis was $3 \mathrm{~min}$ ). The increase in electrolyte concentration results in coarsening of the morphological features. One can see that the samples treated at low electrolyte concentrations ( 2 and $4 \mathrm{~g} / \mathrm{l}$ ) show fine porous morphology, while the samples treated at intermediate and high electrolyte concentrations show coarse porous morphology. This observation was done on each series of the samples treated at a certain fixed time.
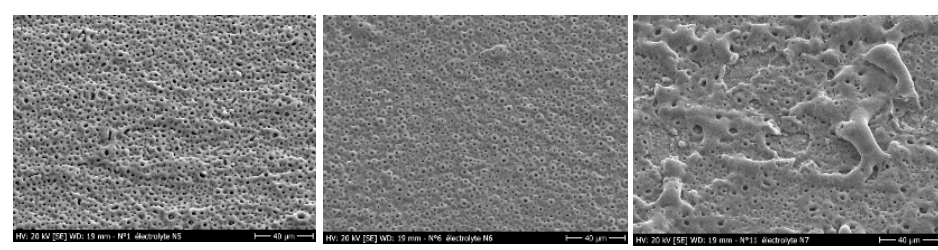

$2 \mathrm{~g} / \mathrm{l}$

$4 \mathrm{~g} / 1$

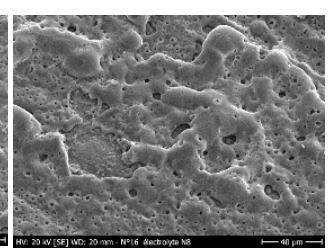

$8 \mathrm{~g} / 1$

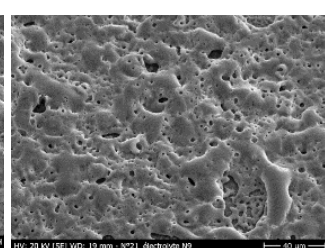

$10 \mathrm{~g} / \mathrm{l}$ 
Figure 5. Evolution of surface morphology of anodized titanium samples with electrolyte concentration (time of electrolysis $3 \mathrm{~min}$ ). For each time of electrolysis $(6,9,12$ and $15 \mathrm{~min}$ ) the surface morphology show similar trend with increasing electrolyte concentration.

The relative area of pores (in \%), calculated from numerical treatment of SEM images, is analysed as a function of time of electrolysis at a constant electrolyte concentration of $2 \mathrm{~g} / \mathrm{l}$ (Figure 6a) and as a function of electrolyte concentration at a constant time of electrolysis of 3 min (Figure 7a). The Gaussian pore distribution function of the layers obtained at different electrolysis times and different electrolyte concentrations are presented in Figures $6 \mathrm{~b}$ and $7 \mathrm{~b}$, respectively.

It has been observed that with an increase of the time of electrolysis, the surface porosity decreases down to $3 \%$. For thick layers (time of electrolysis 12 and $15 \mathrm{~min}$ ), the pore size is irregular, it varies between some square nanometers up to $9 \mu \mathrm{m}^{2}$ with no predominant occurrence of a certain pore size. To the contrary, thinner layers (time of electrolysis 3 and 6 min) show predominately small pores of about $1 \mu \mathrm{m}^{2}$ in size. This behaviour is typical for the layers obtained by anodic spark deposition [14].
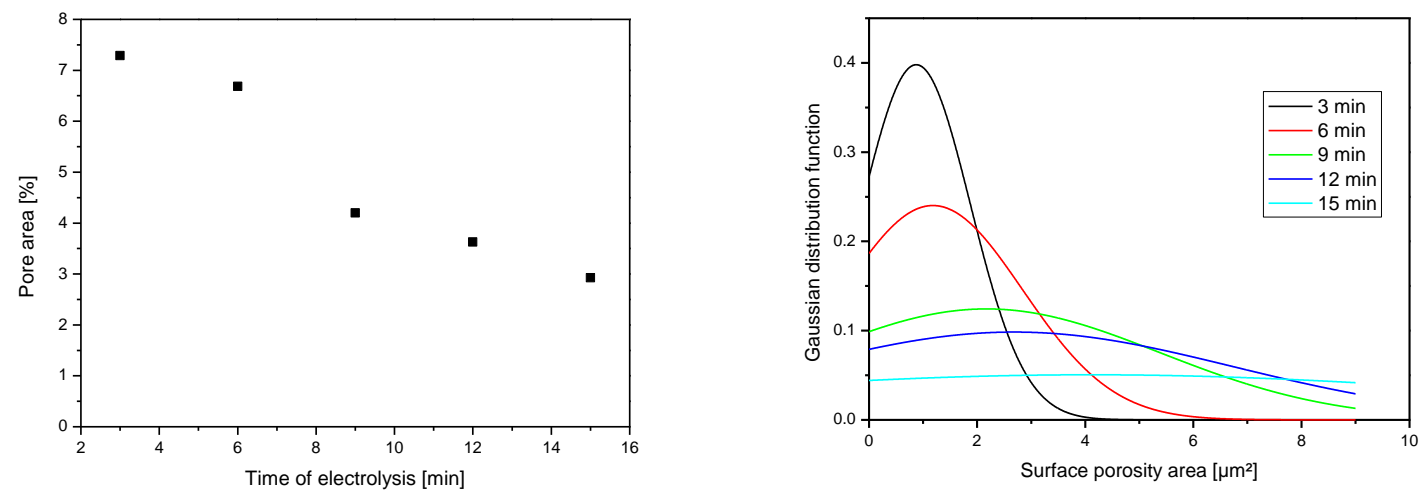

Figure 6. Evolution of relative pore surface area (\%) with time of electrolysis (a). Gaussian pore distribution function for different coating thicknesses (b).

The electrolyte concentration was $2 \mathrm{~g} / \mathrm{l}$

For each set of samples, obtained at a certain time of electrolysis, the decrease of relative pore area with electrolyte concentration was observed. For the samples treated at a constant time of electrolysis of $3 \mathrm{~min}$ and with different electrolyte concentrations, the maximum pore area of 
$7 \%$ was observed for the sample treated at electrolyte concentration of $2 \mathrm{~g} / \mathrm{l}$. For the samples treated at higher electrolyte concentrations (4-10 g/l), the pore area is much lower, between 2 and 3\%. For the layers obtained with low electrolyte concentration ( 2 and $4 \mathrm{~g} / \mathrm{l})$, the predominant pore size is about $1 \mu \mathrm{m}^{2}$. Surprisingly, the lowest data scattering was obtained for the sample treated with electrolyte concentration of $4 \mathrm{~g} / \mathrm{l}$, and not $2 \mathrm{~g} / \mathrm{l}$, as expected. For the layers obtained at higher electrolyte concentrations (6-10 g/l), the pore size is irregular, varying between some $\mathrm{nm}^{2}$ up to $9 \mu \mathrm{m}^{2}$ with no predominant occurrence of a certain pore size.
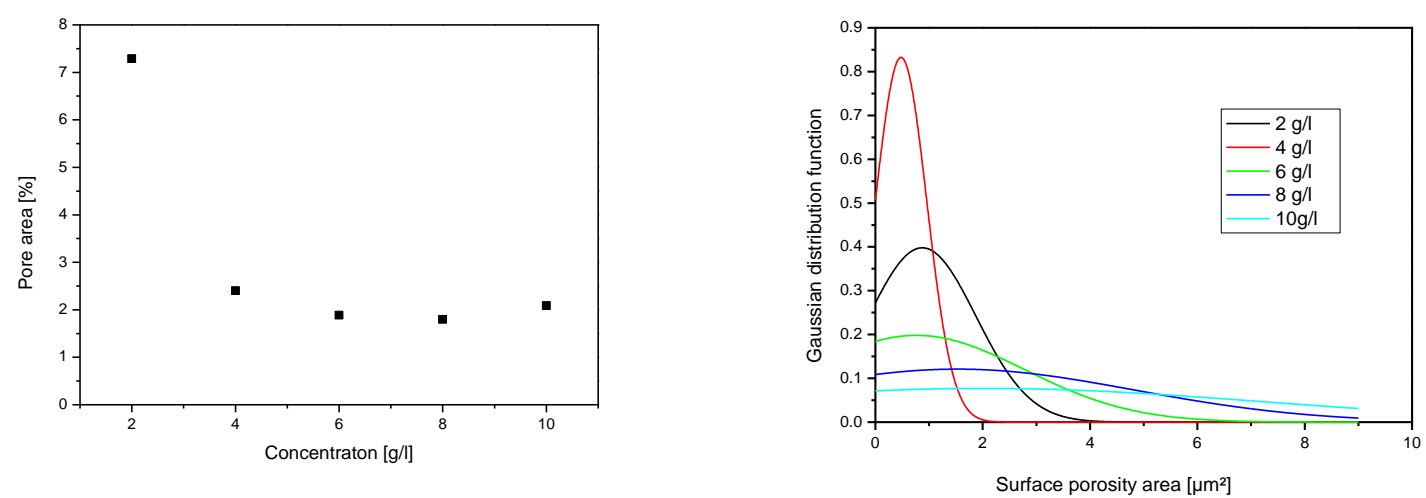

Figure 7. Evolution of relative pore surface area (\%) with electrolyte concentration (a). Gaussian pore distribution function for different electrolyte concentrations (b). The time of electrolysis was 15 min.

Similar trends have been observed for other samples anodized during other time periods and at other electrolyte concentrations.

\subsection{Chemical composition}

Figure 8 shows a typical EDS spectra of an anodized coating. The peaks of $\mathrm{P}$ and $\mathrm{Ca}$ are clearly seen at the spectrum, which confirms the incorporation of these elements into anodized layer. Figure 9 shows the evolution of $\mathrm{Ca}$ and $\mathrm{P}$ concentration in the coatings with its thickness for the coating obtained at different electrolyte concentrations. Both $\mathrm{Ca}$ and $\mathrm{P}$ content increase with increase of the coating thickness. It can be explained by the fact that Ti signal, measured by $\mathrm{XRF}$, decreases with coating thickness, as X-rays penetrate less and less into Ti substrate. To the contrary, with increasing coating thickness XRF response comes preferentially from the 
layer, artificially increasing the $\mathrm{Ca}$ and $\mathrm{P}$ signal as compared to Ti one. The atomic ratio of $\mathrm{Ca} / \mathrm{P}$ is only slightly dependent on the coating thickness, ranging between 0.35 and 0.45 . Note that the values of $\mathrm{Ca} / \mathrm{P}$ ratio obtained with $\mathrm{Ca}_{3}\left(\mathrm{PO}_{4}\right)_{2}$ solution are rather low as compared to the targeted $\mathrm{Ca} / \mathrm{P}$ values. It was established that the optimum value of $\mathrm{Ca} / \mathrm{P}$ ratio should be 1.67 to reach a good biocompatibility with bone tissue [15]. Therefore, it can be concluded that using this type of electrolyte and under experimental conditions studied it is impossible to reach higher values of $\mathrm{Ca} / \mathrm{P}$.

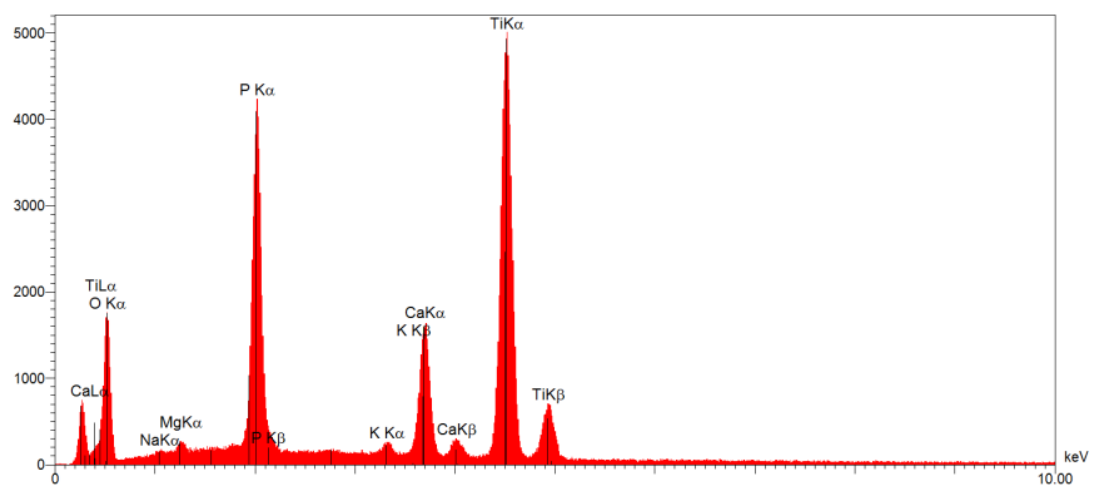

Figure 8. Typical EDS spectrum of an anodized layer showing the presence of $\mathrm{Ca}$ and $\mathrm{P}$ In order to understand the elemental distribution in an anodized layer, the in-depth EDS cartography scan of major elements (Figure 9) was performed on the same layer shown in Figure 3.

As shown in Figure 9, the O, P and Ti elements are uniformly distributed through the whole anodized layer, while $\mathrm{Ca}$ concentration is not homogeneous. $\mathrm{Ca}$ is apparently absent in the thin $(5 \mu \mathrm{m})$ barrier type layer close to the bulk titanium substrate. This might be due to the fact that Ti privileges the formation of $\mathrm{TiO}_{2}$ and $\mathrm{Ti}_{3}\left(\mathrm{PO}_{4}\right)_{4}$ during the early stages of oxidation. Later, Ca-containing compounds, like $\mathrm{CaTiO}_{3}$, calcium phosphates and calcium hydrophosphates are formed along with $\mathrm{TiO}_{2}$. 



Figure 9. EDS cartography scans illustrating the distribution of major elements, $\mathrm{Ca}, \mathrm{O}, \mathrm{P}$ and Ti in the anodized layer
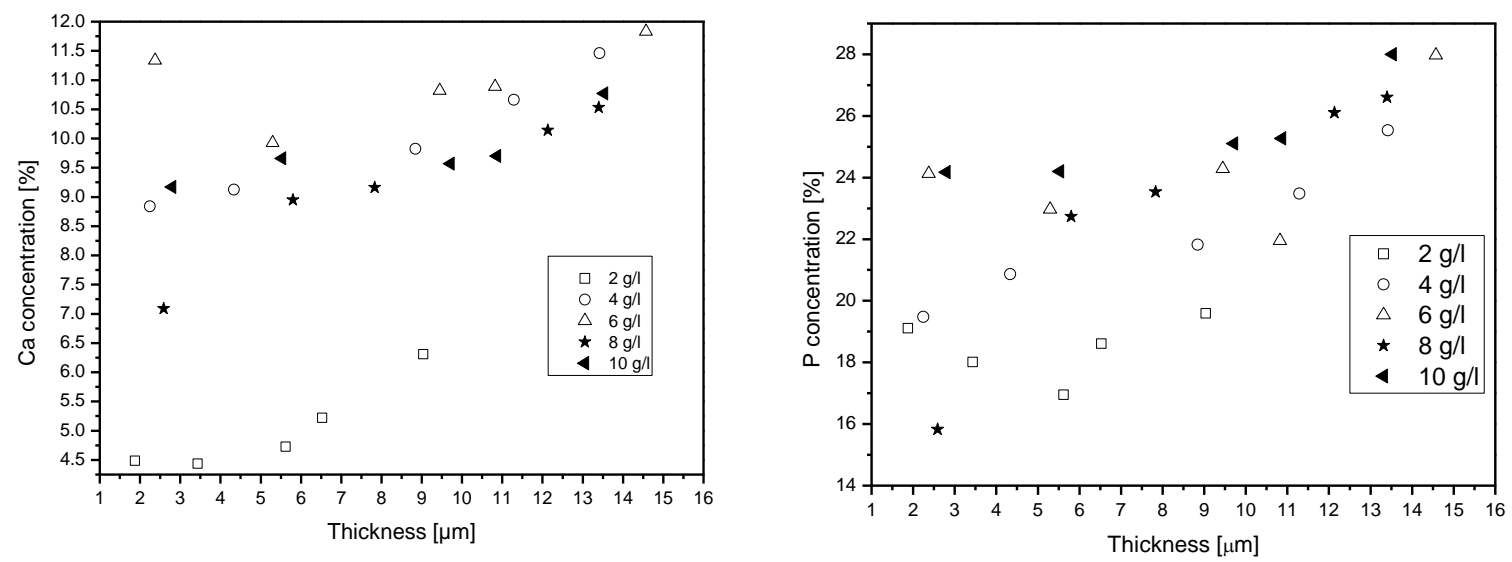

Figure 10. Ca (a) and $\mathrm{P}(\mathrm{b})$ elemental composition (in at.\%) of the samples anodized at different electrolyte concentrations (the standard deviations, estimated to be $10 \%$, are not indicated in the figure for the sake of clarity)

The chemical composition (namely, $\mathrm{Ca}$ and $\mathrm{P}$ content) of the samples was also measured after their immersion in SBF for 14 days. Figure 11 shows a comparison of $\mathrm{Ca} / \mathrm{P}$ ratio of the layers before and after SBF test (measured as $\frac{C_{b}-C_{a}}{C_{b}} \cdot 100$, in $\%$, where $C_{b}$ - concentration in at.\% 
before and $C_{a}$ - concentration after) for all samples studied (independently on time of electrolysis and electrolyte concentration).

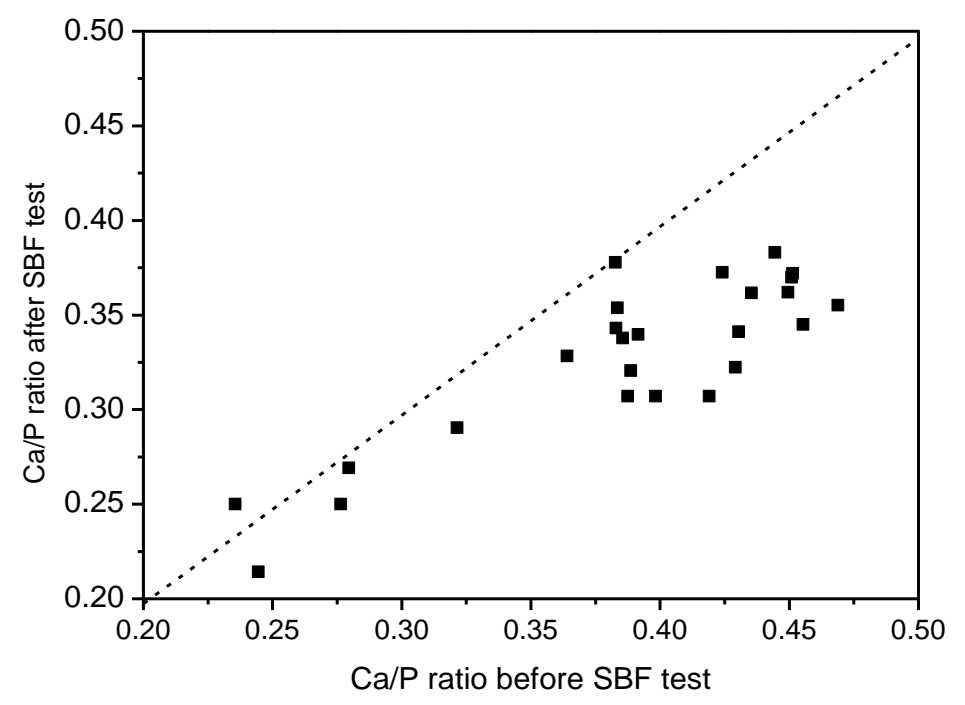

Figure 11. $\mathrm{Ca} / \mathrm{P}$ ratio in the layers before and after $\mathrm{SBF}$ test (independently on time of electrolysis and electrolyte concentration)

It was observed that the $\mathrm{Ca} / \mathrm{P}$ ratio in the layers after $\mathrm{SBF}$ test is always lower than $\mathrm{Ca} / \mathrm{P}$ ratio before test. It can be explained by the higher (5-10\%) dissolution rate of calcium as compared to that of phosphorous. Moreover, it was observed that $\mathrm{Ca}$ and $\mathrm{P}$ loss occurs faster in thin layers (50-70\%), while thicker coatings loose relatively less Ca and P (Figure 12).

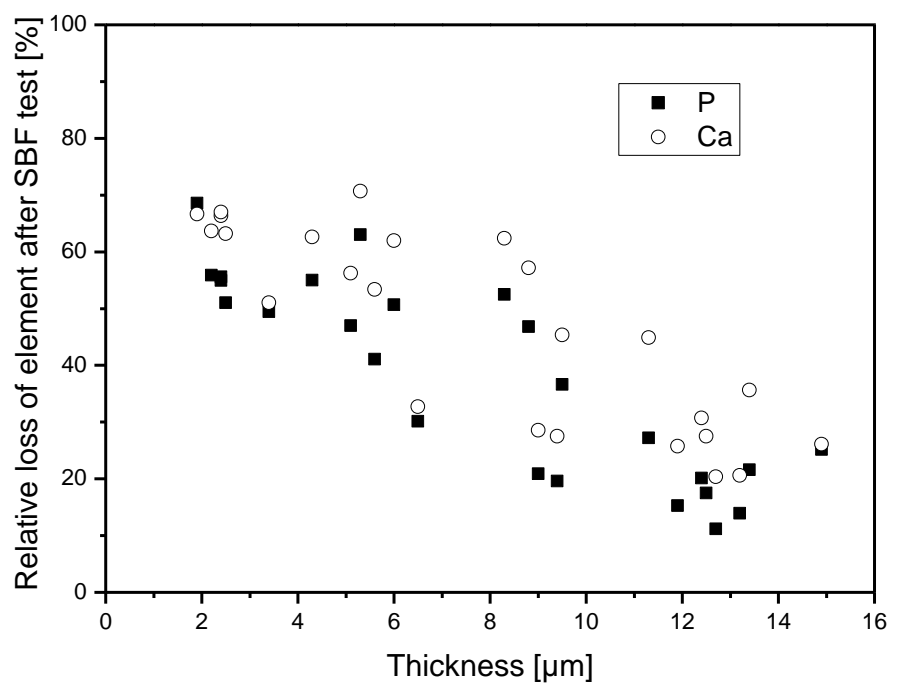


Figure 12. Relative loss (in \%) of $\mathrm{Ca}$ and $\mathrm{P}$ measured after SBF tests with increasing coating thickness (all coatings are presented together)

This conclusion is very important for application issues, while resorbability of the coatings has to be taken into account. It is known [16] that calcium dissolution is an important factor to promote hydroxyapatite (HAP) formation in hard tissue of a human body. Release of calcium and phosphate ions during immersion in SBF accelerate apatite nucleation by increasing the ionic activity product of apatite in SBF.

\subsection{Crystallographic phase analysis}

XRD analysis has been performed on the samples before and after SBF tests. Figure 13 shows XRD patterns for one series of the samples anodized in the electrolyte with concentration of 8 $\mathrm{g} / \mathrm{l}$ during different periods of times. The results do not allow us to clearly detect Ca- and Pcontaining compounds.

The predominant peaks observed in XRD patterns correspond to crystalline $\mathrm{Ti}$ and $\mathrm{TiO}_{2}$ phases. These results let us suppose different actions: 1) a formation of polycrystalline phases of $\mathrm{Ca}$ and $\mathrm{P}$ containing compounds is hindered by the formation of $\mathrm{TiO}_{2}$ phase; 2) the quantity of Caand $\mathrm{P}$ - containing polycrystalline compounds is low; 3) Ca- and P-containing compounds are formed at the surface patly in an amorphous or a low-crystalline forms and therefore are not visible by XRD. A presence of high background at the XRD patterns in the range of $2 \Theta$ between 5 and $20^{\circ}$ supports the latter hypothesis.

All XRD spectra show a clear presence of hexagonal phase corresponding to Ti. This comes mainly from the substrate. It is possible that some residual metallic Ti can be also present in the anodized layer. As the anodization time increases, the coating thickness increases too, and the intensity of the peaks corresponding to $\mathrm{Ti}$ decrease. The Ti substrate is simply buried by the presence of anodized layer.

Meantime, a small peak appearing at $2 \odot \approx 25^{\circ}$ and corresponding to $\mathrm{TiO}_{2}$ (anatase phase), which is not visible at the XRD spectra of the sample oxidised during $3 \mathrm{~min}$, is clearly seen in all other spectra, and corresponding to the samples anodized during higher time periods. Again, the diffraction signal from $\mathrm{TiO}_{2}$ becomes visible with increasing coating thickness.

On the other hand, for a given deposition time, by the observation of the decreasing intensity of $\mathrm{TiO}_{2}$ peaks with increasing concentration of electrolyte (i.e. going from 2 to $10 \mathrm{~g} / \mathrm{l}$ ), it can be concluded that the formation of $\mathrm{TiO}_{2}$ is hindered with increasing concentration of electrolyte. 


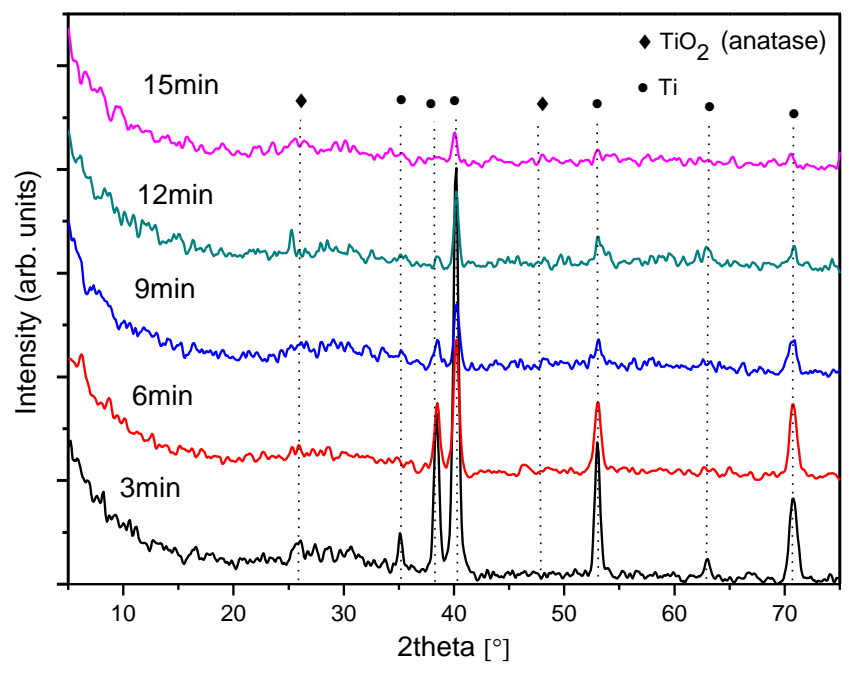

Figure 13. XRD patterns of the samples, anodized during different time periods (electrolyte concentration is $8 \mathrm{~g} / \mathrm{l}$ )

\subsection{Chemical bonds}

Chemical bonding states were investigated on the surface of one sample (treated at electrolyte concentration of $10 \mathrm{~g} / \mathrm{l}$ during $15 \mathrm{~min}$ ) after being immersed in SBF solution for 14 days. Highresolution XPS spectra were collected for $\mathrm{C} 1 \mathrm{~s}, \mathrm{O} 1 \mathrm{~s}, \mathrm{P} 2 \mathrm{p}$, Ti $2 \mathrm{p}$ and $\mathrm{Ca} 2 \mathrm{p}$. Other peaks corresponding to $\mathrm{Na}$ and $\mathrm{K}$ core energy levels were also found on the XPS spectra. These ions were incorporated into the anodized layer during SBF test.

The XPS Ti2p spectrum (Figure 14a) shows the doublet with Ti2 $\mathrm{p}_{3 / 2}$ and Ti2 $\mathrm{p}_{1 / 2}$ at $458.2 \mathrm{eV}$ and $463.9 \mathrm{eV}$ respectively. These peaks are typical for $\mathrm{Ti}^{4+}$ chemical states and can be assigned to $\mathrm{TiO}_{2}$ and titanates (most likely $\mathrm{CaTiO}_{3}$ ) [17].

The XPS spectrum in the O1s region (Figure 14b) shows two peaks at $529.9 \mathrm{eV}$ and $531.9 \mathrm{eV}$. The first peak at $529.9 \mathrm{eV}$ can be assigned to Ti-O bonds occurring in $\mathrm{TiO}_{2}$. The second one, at $531.9 \mathrm{eV}$ is typical for the $\mathrm{P}-\mathrm{O}$ bonds, occurring in $\mathrm{PO}_{4}{ }^{3-}$ ions (phosphates and hydrophosphates) [18]. These ions can come from different salts like $\mathrm{K}_{2} \mathrm{HPO}_{4}, \mathrm{CaHPO}_{4}$, forming during the anodization or/and during the SBF tests.

The XPS P2p spectrum (Figure 14c) shows a strong peak at $133.0 \mathrm{eV}$ which indicates the presence of phosphate $\left(\mathrm{PO}_{4}{ }^{3-}\right)$ ions. Again, these species can be incorporated into the growing layer during anodization process or be formed during SBF tests. 

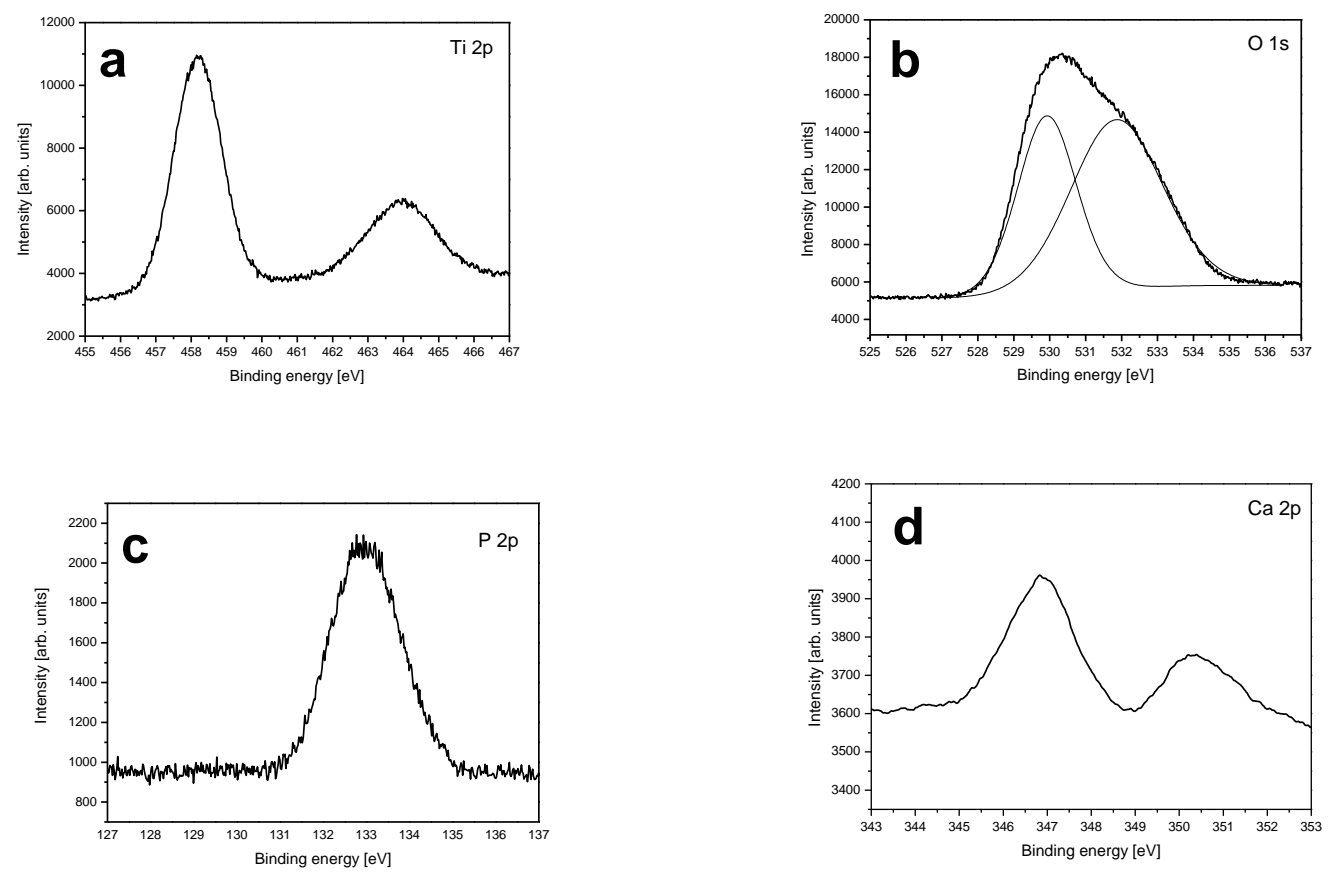

Figure 14. XPS high resolution spectra of the selected anodized layer after being subjected to SBF test: a) Ti 2 p energy window; b) O 1s energy window; c) P 2p energy window; d) Ca 2p energy window.

Finally, the XPS signal related to Ca2p core level (Figure 14d) is very low indicating that its concentration after SBF test is low too. The decrease of Ca concentration due to its dissolution in SBF during the immersion test was already discussed. XPS spectrum exhibits a doublet at $346.8 \mathrm{eV}\left(\mathrm{Ca} 2 \mathrm{p}_{3 / 2}\right)$ and $350.5 \mathrm{eV}\left(\mathrm{Ca} 2 \mathrm{p}_{1 / 2}\right)$, typical for $\mathrm{Ca}^{2+}$ oxidation state. Calcium can be present at the surface in form of $\mathrm{CaTiO}_{3}$ or/and in form of different hydrophosphates $\left(\mathrm{CaHPO}_{4}\right.$, $\left.\mathrm{Ca}\left(\mathrm{H}_{2} \mathrm{PO}_{4}\right)_{2}\right)$.

The chemical composition of the top-surface layer shows 79 at.\% $\mathrm{O}$ and 11 at. \% $\mathrm{Ti}$ (the rest being $\mathrm{P}, \mathrm{Ca}, \mathrm{Na}$ and $\mathrm{K}$ ). The $\mathrm{O} / \mathrm{Ti}$ ratio of 7.2 at the surface is much higher than that corresponding to $\mathrm{TiO}_{2}$ compound $(\mathrm{O} / \mathrm{Ti}=2)$. It confirms our conclusion about a possible formation of O-rich compounds like phosphates and $\mathrm{CaTiO}_{3}$ at the surface.

While, the presence of $\mathrm{CaTiO}_{3}$ at the surface can be supported by the results of XPS, a surface sensitive technique, its presence through the whole oxidized layer is not evidenced. Indeed, 
according to the results of EDS cartography, Ti, $\mathrm{P}$ and $\mathrm{O}$ are homogeneously distributed through the whole layer, while $\mathrm{Ca}$ is mainly concentrated at the surface.

As it was already concluded previously, it is possible that Ca-containing compounds like $\mathrm{CaTiO} 3$, calcium phosphates and calcium hydrophosphates are formed at the latest stages of oxidation process, while $\mathrm{TiO}_{2}$ and $\mathrm{Ti}_{3}\left(\mathrm{PO}_{4}\right)_{4}$, during the early stages of oxidation.

\subsection{Biocompatibility testing}

All surface treatments were tested in terms of cell viability and/or proliferation using resazurin assays. HOBs were seeded on samples with different surface treatments and cell viability was assessed 3 days later. Polystyrene (PS) (more precisely, culture well plate made of polystyrene) was set as reference standard. At day 3, all samples permitted the cell adhesion and cell growth at the level of PS reference ( $\sim 5 \%$ of resazurin reduction). In the test wells (plates were put in the bottom of standard polystyrene 24-well dishes and didn't covered the entire plastic surface; hence some cells were seeded not only on plates but also on plastic), cells that grew on PS reached contact to the metallic samples without any inhibition and/or morphological signs of suffering - apoptosis - necrosis.

The cell proliferation on one selected anodized sample (treated during $6 \mathrm{~min}$ at the electrolyte concentration of $6 \mathrm{~g} / \mathrm{l}$ ) was assessed up to 21 days after seeding. The choice of this sample was arbitrary. At day 3 and 7, values were equal on the anodized sample and PS (5 and 10\% of resazurin reduction, respectively) (Figure 15).

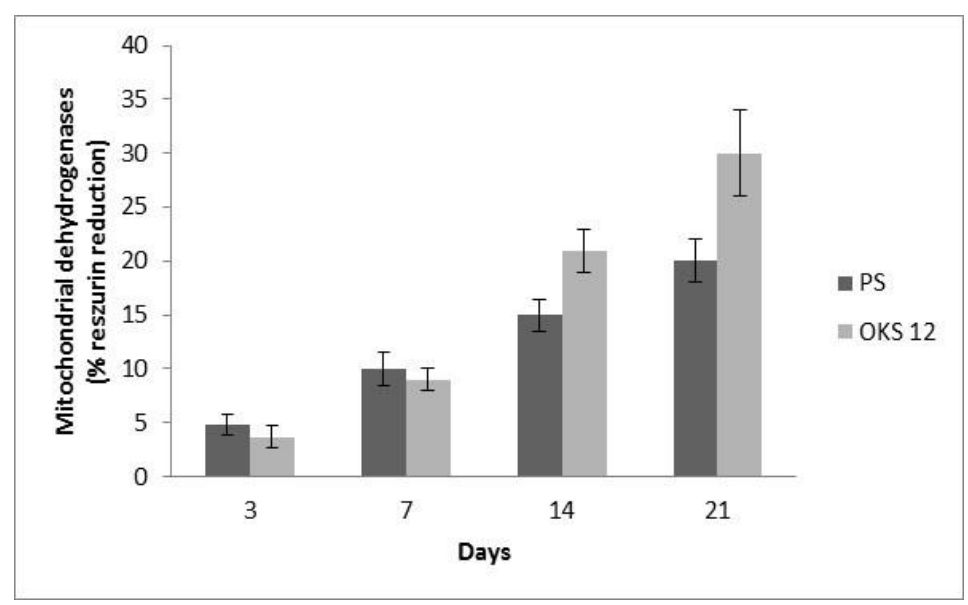

Figure 15. Bioactivity of the selected anodized sample in comparison to that of polystyrene (PS) reference sample. Resazurin assay of HOBs grown on PS and the selected anodized sample (mean +/- SE, $\mathrm{n}=3)$ 
Within the second week of culture until the end, the cell number on the sample exceeded that on PS by 1.5 times, suggesting excellent biocompatibility properties, and even stimulating effects on osteoblasts proliferation. Note that when using sand-blasted and acid-etched (SLA) titanium, a "gold standard" for osseointegration, cells usually under-proliferate when compared to PS during the first two weeks of culture [13]. Further experiments assessing cell morphology, proliferation, differentiation and gene expression are needed to comfort these encouraging preliminary results.

\section{Conclusions}

Commercially pure (CP-4) titanium samples were anodically oxidised by the anodic spark oxidation in the electrolyte containing $\mathrm{Ca}$ and $\mathrm{P}$ ions. Two process parameters, namely time of electrolysis and electrolyte concentration, were varied in order to obtain samples with different surface characteristics. The cross-section layer morphology shows a thick layer substrate interface followed by a thick base layer. The surface of the anodized layers shows a porous morphology. Increasing the time of electrolysis and the electrolyte concentration both result in the pore coarsening. These process parameters also influence the pore size distribution.

The incorporation of $\mathrm{Ca}$ and $\mathrm{P}$ ions into a growing oxide layer was confirmed by means of XRF and EDS analyses. However, while Ti, $\mathrm{O}$ and $\mathrm{P}$ are uniformly distributed in an oxidized layer, $\mathrm{Ca}$ is absent in the thin layer close to the interface. mainly present in the thick base layer. It might be explained by the fact that in the beginning of the oxidation process titanium forms most likely two major phases, $\mathrm{TiO}_{2}$ and $\mathrm{Ti}_{3}\left(\mathrm{PO}_{4}\right)_{4}$. Then other compounds, like calcium phosphates, calcium hydrophosphates and $\mathrm{CaTiO}_{3}$ are incorporated into the base $\mathrm{TiO}_{2}$ layer. $\mathrm{Ca}^{2+}$ ions and $\mathrm{PO}_{4}$ groups are detected by XPS at the top-surface layer. The crystalline phase identification has not revealed any presence of crystalline $\mathrm{Ca}$ - and $\mathrm{P}$ - containing compounds. Only the titanium hexagonal phase ( $\mathrm{Ti}$ substrate) and $\mathrm{TiO}_{2}$ anatase polycrystalline phases were identified by XRD. It can be concluded that $\mathrm{Ca}$ - and $\mathrm{P}$ - containing phases should be present in an amorphous or in a low-crystalline forms.

The $\mathrm{Ca} / \mathrm{P}$ atomic ratio in the layers is varying from 0.23 to 0.47 . These values are much lower than those of hydroxyapatite (typically 1.67). It indicates that the coatings should be highly resorbable in a biological medium. 
The surface properties of the anodized layers were studied after their immersion in SBF solution. After SBF test, $\mathrm{Ca}$ and $\mathrm{P}$ content in the surface layers decrease. Moreover, $\mathrm{Ca}$ and $\mathrm{P}$ loss occurs faster in thin layers (relative loss of 50-70\%), while thicker coatings loose relatively less $\mathrm{Ca}$ and $\mathrm{P}(20-40 \%)$. This conclusion is very important for application issues, as the resorbability of the coatings has to be taken into account.

The biological response of the samples was also evaluated by means of cell proliferation up to 21 days after seeding. At day 3 and 7, values were equal on the anodized sample and polystyrene reference sample. Within the second week of culture until the end, the cell number on the sample exceeded that on PS by 1.5 times, suggesting excellent biocompatibility properties, and even stimulating effects on osteoblasts proliferation. Further experiments assessing cell morphology, proliferation, differentiation and gene expression are needed to comfort these encouraging preliminary results.

\section{Acknowledgements}

The authors wish to thank Mr. Pierre-Alain Montandon and Florian Telmont (both Haute Ecole Arc Ingénierie) for performing sample polishing and XPS analyses, respectively.

This project was founded by the Swiss National Science Foundation under the SCOPES project (grant no. IZ73Z0_152399). 


\section{References}

1. C.N. Elias, J.H.C. Lima, R. Valiev, M.A. Meyers, Biomedical applications of titanium and its alloys. Review, J. Min. Met. Mat. S. (TMS) Biological Materials Science, March (2008) 4649. Available on www.tms.org/jom.html ISSN: 1047-4838.

2. V.M. Frauchiger, F. Schlottig, B. Gasser B., M. Textor, Anodic plasma-chemical treatment of CP titanium surfaces for biomedical applications, Biomater., 25 (2004) 593 - 606

3. H. Ishizawa, M. Ogino Formation and characterization of anodic titanium-oxide films containing Ca and P, J. Biomed. Mater. Res. 29 (1) (1995) 65-72.

4. S. Dorozhkin, Calcium orthophosphates, J. Mater. Sci. 42 ( 2007) 1061-1095.

5. S. Dorozhkin, Calcium orthophosphate coatings on magnesium and its biodegradable alloys, Acta Biomater., 10 (2014) 2919-2934.

6. Y. Gao, A. Yerokhin, A. Matthews, Effect of current mode on PEO treatment of magnesium in Ca and P-containing electrolyte and resulting coatings, Appl. Surf. Sci. 316 (2014) 558-567.

7. D. P. Kashima, A. Rakngarm, Calcium phosphate film coating on titanium substrate by electrochemical deposition, J. Min. Met. Mat., 18 (1) (2008) 27-31.

8. M.H. Prado Da Silva, J.H.C. Lima, G.A. Soares, C.N. Elias, M.C. Andrade, S.M. Best, I.R. Gibson, Transformation of monetite to hydroxyapatite in bioactive coatings on titanium, Surf. Coat. Technol. 137 (2001) 270-276.

9. L. Galois, D. Mainard Bone ingrowth into two porous ceramics with different pore sizes: An experimental study, Acta Orthop. Belg., 70 (2004) 598-603.

10. A. Lugovskoy, S. Lugovskoy, Production of hydroxyapatite layers on the plasma electrolytically oxidized surface of titanium alloys, Mater. Sci. Eng., C 43 (2014) 527-532.

11. M.M. Hossain, W. Gao, How is the Surface Treatments Influence on the Roughness of Biocompatibility? Trends Biomater. Artif. Organs. 22(3) (2008) 144-157.

12. E. Sandrini, R. Chiesa, G. Rondelli, M. Santin, A. Cigada, A novel biomimetic treatment for an improved osteointegration of titanium, J. Appl. Biomater. Biomec., 1 (2003) 33-42.

13. S. Durual, F. Pernet, P. Rieder, M. Mekki, M. Cattani-Lorente, H. W. A. Wiskott Titanium nitride oxide coating on rough titanium stimulates the proliferation of human primary osteoblasts, Clin. Oral Impl. Res. 22 (2011) 552-559. 
14. Q. Li, J. Liang, Q. Wang, Plasma Electrolytic Oxidation Coatings on Lightweight Metals, Modern Surface Engineering Treatments. Ch. 4. INTECH (2013) 75-99. Available on http://dx.doi.org/10.5772/55688

15. Biomaterials for Tissue Engineering Applications. A Review of the Past and Future Trends.

Ed. by J. A. Burdick and R.L. Mauck. Springer-Verlag Wien (2011) X, 564 p. DOI 10.1007/978-3-7091-0385-2

16. G. Wang, H. Zreiqat, Functional coatings or films for hard-tissue applications. Review. Materials (2010) 3994-4050, manuscripts; doi:10.3390/ma3073994. Available on www.mdpi.com/journal/materials.

17. J. P. Schreckenbach, G. Marx, F. Schlottig, M. Textor, N.D. Spencer, Characterization of anodic spark - converted titanium surfaces for biomedical applications, J. Mater. Sci. Mater. In Med. 10 (1999) 453-457.

18. W. Simka, A. Iwaniak, G. Nawrat, A. Maciej, J. Michalska, K. Radwanski, J. Gazdowicz, Modification of titanium oxide layer by calcium and phosphorus, Electrochim. Acta 54 (2009) 6983-6988. 


\section{Figure captions}

Figure 1. Thickness of the anodized layer as a function of anodization time (for different electrolyte concentrations)

Figure 2. Thickness of the anodized layers as a function of electrolyte concentration (the samples were treated during different periods of time)

Figure 3. Cross-section SEM photograph of the sample anodized during $15 \mathrm{~min}$ at electrolyte concentration of $10 \mathrm{~g} / \mathrm{l}$

Figure 4. Evolution of morphology of anodized titanium samples with anodization time (electrolyte concentration $2 \mathrm{~g} / \mathrm{l}$ )

Figure 5. Evolution of surface morphology of anodized titanium samples with electrolyte concentration (time of electrolysis $3 \mathrm{~min}$ ). For each time of electrolysis $(6,9,12$ and $15 \mathrm{~min}$ ) the surface morphology show similar trend with increasing electrolyte concentration

Figure 6. Evolution of relative pore surface area (\%) with time of electrolysis (a). Gaussian pore distribution function for different coating thicknesses (b). The electrolyte concentration was $2 \mathrm{~g} / \mathrm{l}$

Figure 7. Evolution of relative pore surface area (\%) with electrolyte concentration (a). Gaussian pore distribution function for different electrolyte concentrations (b). The time of electrolysis was $15 \mathrm{~min}$

Figure 8. Typical EDS spectrum of an anodized layer showing the presence of $\mathrm{Ca}$ and $\mathrm{P}$

Figure 9. EDS cartography scans illustrating the distribution of major elements, $\mathrm{Ca}, \mathrm{O}, \mathrm{P}$ and $\mathrm{Ti}$ in the anodized layer

Figure 10. Ca (a) and P (b) elemental composition (in at.\%) of the samples anodized at different electrolyte concentrations. (The standard deviations, estimated to be $10 \%$, are not indicated in the Figure for the sake of clarity)

Figure 11. $\mathrm{Ca} / \mathrm{P}$ ratio in the layers before and after SBF test (independently on time of electrolysis and electrolyte concentration).

Figure 12. Relative loss (in \%) of $\mathrm{Ca}$ and $\mathrm{P}$ measured after SBF tests with increasing coating thickness (all coatings are presented together)

Figure 13. XRD patterns of the samples, anodized during different time periods (electrolyte concentration is $8 \mathrm{~g} / \mathrm{l}$ ) 
Figure 14. XPS high resolution spectra of the selected anodized layer after being subjected to SBF test. a) Ti2p energy window; b) O1s energy window; c) P2p energy window; d) Ca $2 p$ energy window.

Figure 15. Bioactivity of the selected anodized sample in comparison to that of polystyrene (PS) reference sample. Resazurin assay of HOBs grown on PS and the selected anodized sample. $($ mean $+/-\mathrm{SE}, \mathrm{n}=3$ ) 